\title{
The British Tradition of Psychoanalysis five Times a Week: Sacrament or Sacred Cow?
}

\author{
Elizabeth Coates Thummel (London)
}

One British analyst says to another, "Have you heard that $X$ is having an affair with one of his patients?" The colleague replies, "Well as long as they are doing it five times a week... what is the problem?"1

\begin{abstract}
The British Psychoanalytic Society (BPAS) is identified with the tradition of psychoanalysis five times a week. The paper discusses the history and evolution of this tradition in the BPAS and how this has been and continues to be supported by various institutional structures including training regulations and subsidies. More recent questioning about frequency is discussed as well as the factors both external and internal that make high frequency analytic work difficult to achieve. Clinical material and illustrations form the basis for discussion of some of the issues involved.
\end{abstract}

Keywords: frequency of sessions, high frequency, psychoanalysis vs. psychotherapy, British Psychoanalytical Society

In the British psychoanalytic tradition, five times a week analysis has been seen as the "gold standard" and remains the cornerstone of training as a psychoanalyst at the British Psychoanalytic Society (BPAS). But the joke points to a tension in this tradition between what I will call the "sacrament" and "sacred cow" points of view. Following one line of argument, five session frequency is regarded as essential to the preservation of a specific method of psychoanalysis and could be thought of as something akin to a sacrament, which, adapting from its Christian origin, I take to mean an outward symbol or ritual denoting an inner mystery of great significance. Alternatively there is a view that the five times a week culture has become more of a sacred cow, an idea held to be immune from criticism, or where questioning could be seen as heretical. In this paper I draw on my experience as 
an analyst in the BPAS, seeing patients at different frequencies from once to five times weekly. This has convinced me of the value of high frequency analytic work with some patients and led me to consider how this can best be supported, but also what can make it so difficult to achieve. Linking with some clinical material I will briefly review some of the ideas and debates that have occurred about frequency in psychoanalysis along with my own reflections on the evolution of this tradition.

But to begin at the beginning, where does this strange idea of five times a week come from? Freud seems only once to have put in writing his thoughts about frequency. In 1913 in one of the papers on technique he wrote:

I work with my patients every day except on Sundays and public holidays - that is, as a rule, six days a week. For slight cases or the continuation of a treatment which is already well advanced, three days a week will be enough. Any restrictions of time beyond this bring no advantage either to the doctor or the patient; and at the beginning of an analysis they are quite out of the question. Even short interruptions have a slightly obscuring effect on the work. We used to speak jokingly of the "Monday crust" when we began work again after the rest on Sunday. When the hours of work are less frequent, there is a risk of not being able to keep pace with the patient's real life and of the treatment losing contact with the present and being forced into by-paths. (Freud, 1913, p. 127)

The only other mention I have found of the frequency with which Freud saw patients comes from the recollections of Abram Kardiner who had analysis with Freud (Kardiner, 1977, pp. 17-18). ${ }^{2}$ He describes how he was one of six patients who had travelled to Vienna for analysis with Freud, but Freud only had 30 hours available for them. After consulting with his wife and daughter, Freud came back with a proposal from Anna Freud that he could see all six patients if he reduced the frequency from six to five days, which is what he did. ${ }^{3}$ As Kardiner comments, "Tradition yielded to expediency. Yet this expediency in its turn became a tradition" (Kardiner, 1977, p. 18).

Interestingly, Kardiner's five sessions were not all consecutive - he had no session on a Wednesday. One suspects this was also expediency on Freud's part, although it is pertinent to more recent debates about whether or not it is advantageous to see less intensive patients on consecutive days or spread over the week. The former approach gives an experience potentially closer to high frequency 
analysis (only one night between sessions) but inevitably a longer "weekend" break and more difficulty re-engaging after the break, Freud's "Monday crust." (see Freud 1913 above). The latter approach might foster working through between sessions and provide greater support due to the shorter "weekend" gap.

In Britain the commitment to 5 times per week analysis was formally enshrined in the training of psychoanalysts established at the BPAS in 1926; the training, as noted earlier, continues to be based on 5 times per week. Students are required to be in their own analysis 5 times per week with a training analyst for at least one year before beginning training and the analysis continues at least until qualification. Students see their two training patients also for 5 times per week analysis. This has been the BPAS tradition not just amongst Kleinian analysts with which it is often associated, but across all groups in the BPAS.

The tradition of 5 times weekly analysis is associated with a clinical approach shared by most British analysts which emphasises the importance of object relations and the detailed consideration of the transference and countertransference. This orientation had its roots in the work of Klein and some of her contemporaries such as Fairbairn, and was later developed by a number of pioneering analysts practising in London from the 1940s such as Winnicott, Segal, Bion, Rosenfeld and Sandler. Many of these analysts were also closely involved in psychoanalysis with children and psychotic patients. Although the latter was not entirely successful in its therapeutic effect, this work led to a particular focus on and an understanding of the more primitive, infantile or psychotic aspects of the personality in a wider range of patients. The theoretical developments that resulted informed a particular approach to so called "deep" clinical work which is predicated on the particular intensity and containment function of 5 times per week analysis. Indeed, some have argued that it was the necessary condition for such work.

From a cultural perspective, the BPAS enjoyed its heyday between the 1940s and 1980s. It was in this period that many, in Britain and abroad, viewed the Society as a leading force in the psychoanalytic world. It is interesting to consider why this period of intense creativity occurred at this time and in the BPAS rather than elsewhere. The BPAS was one of the earliest psychoanalytic societies and always had strong links with Freud through its founder Ernest Jones, one of Freud's closest associates, even before Freud moved to London in 1938. Many other European countries were occupied during the Second World War, resulting in the curtailment of their psychoanalytic culture and education, a subsequent slow process of recovery and working through, as well as a massive exodus of analysts from central Europe to the Americas. Britain was of course not occupied, but the BPAS had its 
own famous conflicts in the Controversial Discussions in the 1940s between supporters of Klein and Anna Freud. Strikingly, given the fall-out from such disputes in other countries, the BPAS did not split but managed, perhaps with characteristically British diplomacy or "fudging," to continue to exist as one Society. It is interesting to speculate how much the legacy of these conflicts, in part concerned with a dispute over who were Freud's true inheritors, led to the reinforcement of the staunch commitment to the tradition of 5 times a week and the view of the BPAS as an elite Society, admired for the depth and quality of its clinical work. Is this the point at which the high frequency tradition perhaps began sometimes to take on aspects of a "sacred cow"?

However in recent years the centrality of 5 times per week has been questioned in the BPAS as well as in many other parts of the psychoanalytic world, and there have begun to be changes. One of the main reasons cited is the difficulty of finding suitable five times a week patients. The changes thus contrast with, for example, the French model where a theoretical position has developed for seeing patients at a lesser frequency. In 2013 the rules for becoming a Fellow at the BPAS were amended to allow some flexibility for patients seen 4 and not just 5 times per week to be accepted. For nearly a century the BPAS was the only psychoanalytic society recognised by the International Psychoanalytic Association (IPA) in Britain. In 2006 the newly formed British Psychoanalytic Association (BPA) was formally recognised by the IPA and began training psychoanalysts in 2009. One of the differences between the two trainings was that the BPA required only 4 sessions per week both for their students' own analysis and that of their training patients.

Many psychoanalysts in Britain now have a mixed practice which includes patients seen across the range of frequency from once to five times a week. There is no state health insurance available for psychotherapy or psychoanalysis in Britain, so all patients seen in private practice are paying their own fees. There are also well respected and long established trainings in psychoanalytic psychotherapy, usually at 3 sessions per week. Within the National Health Service patients are seen for psychotherapy, but now usually only once a week and for a limited period of one to two years.

\section{Clinical material}

In order to illustrate what I see as the value of high frequency analysis, I will describe work with a patient Mr A who began psychotherapy twice a week on consecutive days, later progressing to 4 session analysis. An intelligent and talented man with a successful professional and social life, Mr A had long been 
plagued by not knowing what he wanted or even what he really felt. He suffered chronic low level anxiety and tended to feel estranged in intimate relationships and often spoke of an experience of facing a cliff that he could not penetrate, or of confronting a wall with no door.

He attended his sessions regularly. For a long while it felt the therapy was going along nicely - he became more insightful, and links were made with his early history. He was appreciative of what he called "our interesting conversations." However increasingly I felt that something was too comfortable and rather stuck. At times he would seem to talk to himself in my presence, shutting me out, not really needing or wanting my interventions, even becoming resentful if I said something new which he had not thought of himself. Sometimes I found myself letting him go on, feeling rather detached but also vaguely guilty that there was something I was not doing. In the transference I was a romantic fairytale figure who would lift him up or help him down but always so he could be alongside me, the fairytale prince and princess (he was an avid reader of romances in his adolescence).

Both the patient and I felt that good work had been done; his sense of shame and fear of rejection had come much more into the open, and his tendency towards grandiosity seemed more amenable to understanding. But I felt increasingly confined by my "princess" qualities of being understanding both of the neglected, anxious little boy part of him, and of the pompous, arrogant contemptuous intellectual. I became increasingly aware of the patient's subtle denigration of me and my role and his persistent need to keep me at a distance. One aspect of this was that he knew I was an analyst and he knew about analysis but every time I broached the possibility of increasing his sessions he would rather lightly brush this aside - he was too busy and it would take up too much time. There were times when I felt I could get closer to addressing some of the more destructive aspects underlying his anxiety, but he would then become frightened and panicky, describing me as "holding his head underwater." These moments of deeper and more uncomfortable contact would be quickly lost however in a return to intellectualisation, or would be disrupted by the long break between sessions.

I slowly came to feel that the stuckness of the work was linked to the limitations of the setting with twice weekly work. He used the couch and one day he began to bring a book from the waiting room that he put under his back. Ostensibly this was because of back pain as he found the couch "too soft." For months I could not understand the significance of this, which he dismissed as purely physical. But I eventually began to think about there being a communication about a softness that took me over and prevented me from more robustly taking up the refusal to 
have more sessions. I realised how much I was caught in my assigned role of the warm permissive maternal figure (in contrast to a cold critical mother he felt he had grown up with) and my identification with an aspect of the patient paralysed by a profound doubt about being loved or wanted. This translated into my own doubt about whether a full analysis - that is more of me - was what the patient needed.

I began to interpret this to the patient and to show him how his dismissal of the possibility of more sessions was a way of keeping me at a distance and subtly denigrated, linking this to the ways he was now able to recognise he had shut himself out from relationships in the past. He was very moved by this understanding. Over time he came to be much more in touch with a sense of grief and an awareness of the hurt he had inflicted on those he loved. He could see much more clearly how he evaded closeness but at the same time became increasingly aware of how painfully he felt himself to be missing out on something. This period of work - still at twice a week - went on for about a year. There was a slow shift in both of us as we explored more explicitly what a move to analysis would mean. I became more robust in interpreting his wish to stay in a comfortable fantasy rather than risk the reality of meeting with me more often. He became increasingly anxious. In the transference the imagery became much darker, as I was more often felt to be intrusive and threatening and he felt himself to be dirty and ashamed. In dreams he was represented as a black worm stuck in a shell and I was sticking a pin into the flesh inside the shell and pulling it out, revealing a long black thread of excrement. Or I was cast as the one pushing open the toilet door while he was defecating. On the other side he became more open in his denigrating defences - once arriving to a session and referring to a parking notice outside the consulting room which he took to be saying "cheap psychotherapy available here."

However, despite this more open and moving exploration, Mr A still found it difficult finally to ask for more sessions even when I told him that suitable hours would soon be available. He seemed unable to put an end to the prevarication. Around this time he brought a helpful dream:

There was a battle between Frederick the Great and the Austrians, although it began as a re-enactment with people dressing up as soldiers and conducting the war in rather elegant rooms. But from a balcony the patient could see the (real?) Austrians coming across the river towards them. The patient left the room and when he returned he found all the Prussians horribly killed. An old friend had a very sharp knife and began slicing layers of skin 
off the patient's thumb. The patient then took the knife and cut from the man's mouth through his cheek, but there was no blood. He turned the knife deeper in the man's jaw.

The patient associated the war to the Seven Years War between the Prussians and the Empress Elizabeth of Austria. He was shocked when I pointed out the link to my name and us being in the 8th year of the therapy. We were able to understand how the battle over the question of more sessions, over my threatened invasion of his territory, was in some respects becoming a phoney war. But at the same time there were very real fears of something murderous being done-either by me to him, intruding and invading with more sessions, or by him to someone whose mouth, and capacity to speak is destroyed. This of course could be my mouth and words or his own. I think this helped bring into the open both the danger of the exploration of the move to analysis becoming a phoney dressed-up sort of argument, but at the same time the very real fear that more sessions represented a horribly brutal intrusion akin to a stabbing or slow slicing castration. A few weeks later the patient was finally able to ask for more sessions and we began the following week with an increase to four.

The change since then has been marked. Mr A brings a wider range of feeling to the sessions, and has been more able to get directly angry with me, for example over charging fees when he was ill and unable to come to his sessions. This led him to recognise how the fees also relate to the reality of my need and my livelihood, and thus to the reality of my separate and independent existence. He is more able to differentiate and articulate feelings in many areas of his life. There have been positive changes in his life externally, for example, he has begun a relationship with a woman where he is much more able to allow himself to feel loved and wanted. He has greater insight into his patterns of relating and more awareness of others' separateness and difference. The changes in his internal world are illustrated in a dream which included the image of a pleasant beach with a sloping cliff face, a holiday house perched among greenery. This contrasts with the impenetrable cliffs or doorless walls that had so frequently featured in the past and which were felt to conceal either something dangerous, volcanic and deadly or an idyllic paradise world that was inaccessible.

The example of Mr A is of a move to analysis 4 not 5 times a week. This raises the tricky question of what is the difference between 4 and 5 times work. Four days are more than half the week. Five days are for most people the number of days they go to work. These are simple concrete issues, but I think they make a 
difference. There is a logic to the "work" of an analysis fitting with the prevailing rhythm of work. I am not sure whether, in 1913, when Freud advised working six days with patients, this was in accordance with the culture of work in Vienna at that time. But as Kardiner (see footnote 3 above) and his American colleagues seem to have felt deprived relative to Freud's English patients, so today the 4 times a week patients may wonder why they are not included on the 5th day. The exclusion of a day when the analyst is known or presumed to be working becomes a different exclusion from the weekend where both analyst and patient probably do not work.

A patient progressed from once weekly psychotherapy to analysis four times a week - five times being out of the question due to the patient's work commitment. She made good progress, but later the question was raised in clinical discussion with the analyst of why she did not have a fifth session as her work schedule had now made this possible. This led the analyst to realise that he had resigned himself not even to think about the fifth session. When the analyst raised this with the patient she brought a memory from years earlier of having been very moved by the mention of the potential of analysis five times a week. Despite becoming panicky she was able to take up the fifth session. Soon after the increase her long-standing decision not to have children was shaken by the upsurge of a wish to have a baby, as if the fifth session had allowed something creative to come back to life.

\section{Discussion}

Frequency is one aspect of the analytic setting; the use of the couch, the regularity and strict duration of sessions, the neutrality of the analyst etc might all equally be seen as crucial elements of the analytic frame. For Mr A the frequency of two sessions had become congruent with his defensive system of avoiding deep intimate contact and the concomitant anxieties this evoked; this aspect of the setting had become the location of an enactment between patient and analyst. Importantly this was in the context of his and my awareness of the existence of another model of frequency, namely five times weekly, such that the "missing" or "not yet existing" sessions already had a place in our minds. It was as if we became aware we were dating but afraid of moving in together.

Debates about frequency have often hinged on the question of how to enable a psychoanalytic process to get underway and to be sustained. This seemed to be an essential aspect of Freud's advice quoted earlier. The question then arises of what is meant by a psychoanalytic process? What are its essential ingredients? This question in turn presupposes another: what are the key differences between psychoanalysis and psychoanalytic psychotherapy? This is something which many 
influential analytic writers have addressed (e.g. Kernberg, 1999) and it is beyond the scope of this paper to explore this debate or the difficulties of defining what exactly constitutes a psychoanalytic process. However, I would hope my clinical example demonstrates that I was working and thinking psychoanalytically, even when seeing Mr A twice a week - taking psychoanalytic work at its simplest to mean interpreting the transference and resistance and an awareness of countertransference enactment. Thus the work over the year preceding the increase in frequency involved my recognising the way I had been pulled into adopting a particular role in his defensive structure that was no longer helpful, and interpreting the transference as it was manifest in relation to the number of sessions, as well as his resistance to any change. If I was working psychoanalytically at this point, in what way did the increase to four sessions change this?

Much of the literature on the impact of increased frequency addresses the quantitative change. More hours, more time allows the accrual of more data, the opportunity for patient and analyst to discover more patterns in the detail of the material. Freud also remarked upon the importance of "keep[ing] pace with the patient's real life" (Freud, 1913 above). The patient needs time to convey the details of his/her every day life in external reality. If there is insufficient time there is a risk of the narration of external events taking over or diverting the sessions, "into by-paths" as Freud would say, without space for the internal psychic work of analysis. The patient needs time to run out of things to say. As Ferraro puts this, "the time required to collapse the pressure exerted by external reality" (Ferraro, 2011, p. 143). For Mr A the increased frequency made patterns in his external life and in the transference much harder to avoid. There was less risk that his external preoccupations and intellectualisation dominated the sessions as there was more time for us to recognise their meaning and the extent to which they were being used defensively and why.

But more importantly, higher frequency also results in a qualitative change both in the material and the relationship between patient and analyst. In Winnicott's language, greater holding provides greater scope for regression, or in Bion's terms, greater containment facilitates the emergence of primitive psychotic anxieties. Defences loosen but with usually less risk of acting out outside the sessions. Patients will often bring more dreams and aggressive and destructive aspects are more likely to come to the fore. The intensity of the contact between patient and analyst enables the transference to emerge more clearly to both patient and analyst. One interesting aspect with the shift to four sessions was that Mr A for the first time in his adult life stopped having often overlapping sexual relation- 
ships, but instead for a period of about 18 months remained single and celibate. I understood this as my having become, for a time, the central relationship in his life; he was able to communicate much more of his erotic transference towards me. The stopping of the affairs could be seen as a shift from acting out towards bringing the characteristic object relations and conflicts into the transference. This enabled the patterns of these relationships to be much more convincingly understood, what is sometimes described as being able to work "with" rather than "in" the transference. (Barnett, 1992). My understanding and interpretation really made sense to him as an experience, not just a theory. Another analytic patient who had previously had once weekly therapy with a colleague commented: "I know I missed my therapist when I saw him once a week, but it was easy not to be aware of it. Now [in analysis] it is harder not to be aware."

The increase in frequency can also be thought of as the analyst being able to work differently, at greater depth. There is more evidence on which the analyst can base interpretations, with less risk of "wild" interpreting (Gedo \& Cohler, 1992). It is easier to retain an analytic stance of neutrality that is equidistant from ego, id, superego and external reality, and to recognise and recover from enactments and other counter transference pressures. The supportive effect of a session every working day allows the analyst to risk stronger and more challenging interpretations - with Mr A my "holding his head underwater" - and for these to be tolerated by the patient. There is a chance for recovery and working through of a difficult or inflammatory session by meeting the next day. Thus with Mr A I think the work speeded up with higher frequency not just because of having more time but because I was able more clearly to observe the shifts in transference and countertransference and then interpret with greater conviction and take up his responses. If the gap between sessions is too long, this response becomes harder to discern and disentangle from other events, internal and external, which intervene, what Freud describes (see above) as the "obscuring effect." With the knowledge and safety of a session tomorrow the work can be deeper and more disturbing. For $\mathrm{Mr}$ A the experience of the analysis became much more intense and emotional and less intellectual.

There have been significant debates about frequency over the years (see Conrotto 2011 and Ferraro 2011 for useful summaries). There is also some research evidence, admittedly still tentative and inconclusive, which indicates that increased frequency and duration of analytic work is linked to a better outcome, particularly in relation to the internalisation of the therapeutic relationship and the consequent 
effect on the outcome after treatment ends (see Frosch 2011 for a clear summary of this work).

One recurring theme in the literature relates to the need to achieve an optimal balance between what is stirred when analyst and patient are together and what is evoked by separation and the working through or digesting which takes place away from the analysis. One critique of the 5 times weekly model (e. g. Israël, 1994) is the view that it fosters too great a dependence of the patient on the analyst and an avoidance of separation anxiety, that the analyst would be providing almost a "corrective emotional experience" (Alexander, 1950). Laufer, a British contemporary Freudian analyst, has given a vigorous defence against this argument. Far from being comfortable, she contends, the 5 times weekly model aims

to maximize and intensify the frustration of the desires of the patient for a "real" relationship in order to make the transference desires available to consciousness. (Laufer, 1994, p. 40)

I would agree with Laufer and I think this is illustrated in my work with $\mathrm{Mr}$ A where the comfortableness and reassurance was in many ways more evident in the less intensive period of work. His resistance to the increase in frequency was linked to a wish to stay in his fantasies and not to face the painful frustration of his transference desires that was inevitably intensified with more frequent contact with me. The containment function of the four sessions in a row enabled Mr A to bear the "infantile state of helplessness" (Laufer, 1994, p. 43) aroused by the end of the session representing the curtailment of his desires.

One interesting aspect of the process of moving to analysis with $\mathrm{Mr}$ A was the length of time, eight years, that it took before he or we could make the shift. As I was writing this paper, I became aware of my reluctance to mention the length of time as if there was something shameful and lacking in my skills as an analyst: how had I let the situation continue for so long? When I spoke to the patient about his feeling that I might have gone along with something destructive and stuck in him for too long, he disagreed. He felt he had needed my patience, "like water dripping on a stone" to wait for him to be able to believe that I might genuinely be willing to offer him more and that an analysis might be an opportunity for greater change. There is probably some truth in this. But I think there is also something important about the fears of a full analysis not just in the patient but how these get transferred to the analyst. In the remainder of this paper I will consider what it is 
that makes engaging in a high frequency analysis so difficult for both patient and analyst and what can ameliorate these difficulties, whether external or internal.

\section{External difficulties}

There are undoubtedly socio-economic factors that contribute to the difficulty in finding 5 times weekly patients. The pace of life in Western culture is fast and increasing: the speed and immediacy of digital communication and modern travel, the impact of the recent economic crisis, create an expectation of long hours of work and high levels of stimulation in leisure time which does not sit easily with the slow pace and time demands of a full analysis. In publicly funded mental health services, shorter (and cheaper) treatments such as medication or briefer talking therapies such as cognitive behaviour therapy are in the ascendant. Financial pressures are increasing for many middle class educated people who might be seen as the group most likely to seek analysis privately. And psychoanalysis does not come cheap. Paying for an intensive analysis even at the relatively modest fee of $£ 40$ per session would cost $£ 8000-£ 9000$ per annum, which is about one third of average income in the UK (Office of National Statistics, 2013). Many analysts of course are also experiencing similar financial pressures.

In an unpublished survey in 2011 of BPAS psychoanalysts conducted by Penny Crick, Director of the London Clinic of Psychoanalysis, she found of 62 analysts qualified between 2000 and 2010 seeing a total of 400 patients, only 90 patients $(22.5 \%)$ were undergoing five times per week analysis. ${ }^{4}$ Of these only 36 (40\%) were paying a so-called "full fee" (average $£ 46.93$ ). The other $60 \%$ were subsidised or low fee patients (paying $£ 35$ or less -11 patients paying less than $£ 10$ ). Of those paying a full fee half had only come to have five sessions after building up from psychotherapy at a lower frequency. As Crick concludes

\section{Our relatively newly qualified analysts are not making a living out of working in four and five times weekly analysis. They are getting a lot of experience of seeing analytic patients, but mostly at low fees, and they are mainly earning most of their private practice income from once, twice and three times weekly patients who make up well over half the practices of these analysts. (Crick, 2011)}

One important way of supporting high frequency analysis in Britain is through the provision of subsidies. The London Clinic of Psychoanalysis was established by the BPAS in 1926 to offer low fee analysis 5 times per week to patients 
who could not afford private fees. In recent years the Clinic has been expanded and modernised to provide a comprehensive psychoanalytic consultation service. Patients are seen for consultation by an experienced analyst who makes a recommendation for the appropriate treatment. This may vary between a full analysis either privately or under a low fee scheme where patients pay what they can afford - this can be as little as $£ 5$ per session. Alternatively the consultation may lead to a referral for psychotherapy. Patients seen under the low fee scheme usually become training patients for students training to become psychoanalysts. For the duration of their training the student sees the patient for no fee and the patient's fee is paid to the Clinic. On qualification the patient transfers to the analyst's private practice and the fee may increase although students are expected to continue the analysis of their patient to termination even at a low fee. The Clinic also has a limited number of subsidies for patients seeking analysis privately with a qualified psychoanalyst. These subsidies top up what the patient can pay (currently to $£ 40$ per session) for a period of up to three years, and have recently been also modified to include 4 as well as 5 times per week analysis.

The reality for most British analysts today is that analytic patients have to be subsidised through formal subsidies or the analyst's other income (from psychotherapy patients or other employment as a clinician or academic) and also have to be built up from lower frequency psychotherapy, which is not easy and little written about. Freud, as quoted earlier, would seem to have regarded such an approach as "out of the question."

\section{Internal difficulties}

The internal resistance in the patient and in the analyst to work intensively should not be underestimated. To visit an analyst and pay to lie on their couch, five days a week for years on end is a strange thing to do as much in Freud's time I suspect as it still is in ours. Strachey wrote eloquently in relation to mutative interpretation about the analyst's

...lurking difficulty in the actual giving of the interpretation, for there seems to be a constant temptation for the analyst to do something else instead. (Strachey, 1934, pp. 158-9)

I think there is a similar "lurking difficulty" in the analyst helping a patient have an analysis - presuming of course this is appropriately indicated - with a temptation to do something else, meaning fewer sessions. Whatever our conscious 
beliefs about the value of analysis there can be a powerful resistance to becoming embroiled in deep daily contact with another person's life and internal world. This is our own resistance to the unconscious but can also be a resistance to the responsibility and intensity involved in analytic work, seeing the same person every day of our working week. This means overcoming our doubts and ambivalence to providing a full analysis. Ehrlich (2010) has written sensitively on this subject as a factor that complicates the real external difficulties in finding analytic patients. I agree with her conclusion that

A ubiquitous conflict that the analyst must analyze... is the analyst's ambivalence about practising as an analyst... [P]aradoxically, recognising this ambivalence can strengthen one's analytic identity and increase one's capacity to continue and deepen an analysis. (Ehrlich, 2010, p. 530)

The analyst's own experience of analysis five times a week is in my view a vital resource in this struggle, as is the support of colleagues in supervision or clinical discussion. I have also found that mentioning the possibility of five times a week analysis to patients at the stage of initial consultation can prove important years later. I referred earlier to the symbolic importance of the "missing" sessions for both patient and analyst. The possibility of analysis 4 or 5 times per week being raised at the outset is an important way the presence of "not yet existing" sessions can be created.

A patient took several years to move from once per week psychotherapy to first twice weekly then five times a week. She had been told in her initial consultation with a colleague that she might benefit from full analysis. She had suffered numerous losses early in her life and was understandably cautious and suspicious of involvement with me. But as her trust developed, partly as a consequence of my patience in allowing her to set her own pace, her increasing awareness of the level of her deprivation also enabled her to understand that this strange offer, my willingness to see her every working day for as long as she needed, was a tremendous gift and opportunity that she was eventually able to allow herself to have.

\section{Conclusion}

I have given an account of the British tradition of analysis 5 times per week and how the institutional arrangements of the BPAS and the London Clinic, the structure of regulations and subsidies are an important factor in supporting and 
reinforcing the tradition of 5 times weekly work. I hope I have shown that despite the dangers of something becoming over-rigid and prescribed, the sacred cow, there are real benefits in 4 or 5 times a week analysis. To achieve this requires both internal and external support and a challenge - to our own resistance and to the patient's. The analyst needs to have reached a point of conviction that it is not just orthodoxy that makes 4 or 5 sessions necessary, but that this is genuinely what this patient needs at this time. I think it is only when the analyst has reached a point of genuine conviction that she has any chance of enabling a patient authentically to take up the offer of analysis.

But there is an ever present danger that a healthy challenge transforms into an unhealthy orthodoxy where what is honest and authentic for both analyst and patient is lost. As the joke at the beginning of this paper reminds us it is quite possible to do something five times a week that is not psychoanalysis and may not be for the patient's benefit at all. Good psychoanalytic work (whether or not we call it psychoanalysis) is possible with less frequent sessions than 5 times a week and for some patients this may well be appropriate and right. The attraction of thinking in terms of either the sacrament or the sacred cow is that it provides an escape from difficult thinking. One consequence of writing this paper has been the recognition of the need to keep thinking about frequency with each patient, to stay alert to what it might mean. This is not to say that high frequency analysis should be the goal that we strive to achieve with every patient. This would be a return to the "sacred cow" approach. But frequency, high or low, should be an aspect of the work we explore, and when it has fallen out of view it might be useful to wonder why.

\section{References}

Alexander, F. (1950). Analysis of the Therapeutic Factors in Psychoanalytic Treatment. Psychoanalytic Quarterly, 19, 482-500.

Barnett, R. (1992). Two or three sessions? A discussion of some ideas about the frequency of sessions in psychotherapy. British Journal of Psychotherapy, $8,430-441$.

Conrotto, F. (2011). On the Frequency of Psychoanalytic Sessions: History and Problems. Italian Psychoanalytic Annual, 5, 123-134.

Crick, P. (2011). Revised News from the Clinic: How many patients and at what fee? Report on a survey of analysts qualified 2000-2010, Bulletin of the BPAS (unpublished).

Ehrlich. (2010). The analyst's ambivalence about continuing and deepening an analysis. Journal of the American Psychoanalytic Association, 58, 515-532. 
Ferraro, F. (2011). Some remarks on an ongoing debate: Frequency and rhythm in the analytic process. The Italian Psychoanalytic Annual, 5, 135-156.

Freud, S. (1913). On Beginning the Treatment (Further Recommendations on the Technique of Psychoanalysis 1). Standard Edition, 12, 121-144.

Frosch, A. (2011). The effect of frequency and duration on psychoanalytic outcome: A moment in time. Psychoanalytic Review, 98, 11-38.

Gedo, P. \& Cohler, B. (1992). Session frequency, regressive intensity and the psychoanalytic process. Psychoanalytic Psychology, 9, 245-249.

Israël, P. (1994a). Some Specific Features of the Psychoanalytic Training. Bulletin of the European Psychoanalytic Federation, 42, 29-37.

Kardiner, A. (1977). My analysis with Freud; Reminiscences. New York: Norton and Co.

Kernberg, O. (1999). Psychoanalysis, Psychoanalytic Psychotherapy and Supportive Psychotherapy: Contemporary Controversies. International Journal of Psychoanalysis, 80, 1075-1091.

Laufer, E. (1994). Discussion of Paul Israel's Paper “Some Specific Features of Psychoanalytic Training”. Bulletin of the European Psychoanalytic Federation, 42, 38-45.

Monari, M. \& Resele, L.F. (2011). The spread of low frequency psychoanalysis: Statistical data and comments on the Italian and International psychoanalytic scene. The Italian Psychoanalytic Annual, 5, 157-176.

Strachey, J. (1934). The Nature of the Therapeutic Action of Psycho-analysis. International Journal of Psychoanalysis, 15, 127-159.

\section{Annotations}

1 Eric Brenman, a British psychoanalyst, was the originator of this joke. I am grateful to Daniel Pick for telling it to me.

$2 \quad$ Although Freud does not formally discuss frequency elsewhere, Frank (2011) has helpfully traced the roots in Freud's writing of some of the controversy about frequency.

$3 \quad$ Freud continued to see his English patients at that time (James and Alix Strachey and John Rickman) six days a week; as the American Kardiner observes "We mere Americans could be sacrificed" (ibid., p. 18)!

4 The combined percentage for patients seen in 4 or $5 \mathrm{x}$ per week was $31.5 \%$. This is comparable to figures in an IPA survey (27.9\%) and APsaA survey (31.3\%) (Monari, 2011). 